\title{
EFFECT OF EPOXY ADDITION ON THERMAL CONDUCTIVITY EXPANSION AND PERMEABILITY OF CEMENT MORTAR
}

\author{
*Baraa M. Matlk1
}

\author{
Besma M. Fahad ${ }^{2}$
}

Lubna Ghalib ${ }^{3}$

1) M.Sc. Student, Materials Engineering Department, Al-Mustansiriyah University, Baghdad, Iraq

2) Asst. Prof., Materials Engineering Department, Al-Mustansiriyah University, Baghdad, Iraq

3) Dr., Materials Engineering Department, Al-Mustansiriyah University, Baghdad, Iraq

\begin{abstract}
Ordinary construction materials have many advantage characteristic but also have some limitation such as porosity, moderate thermal insulation. It difficult to modified properties with keep low density. The aim of this work to enhance some insulation properties by the addition of polymer to mortar. Two sets of mixtures were prepared, that consist of mortar and polymer to fabricate the polymer-mortar composites. The first set was cured at room temperature and the other was post-cured at $50^{\circ} \mathrm{C}$ for two hours. Both sets include mortar (cementsand) without water. The selected polymer was epoxy which is added to the mortar using different percentages $(15,20$, and $30 \%)$ by weight. The insulation effect of polymer addition on mortar was studied. The result showed that by adding polymer the density kept low and the lowest density obtained for post-cure at $30 \%$ the polymer which was $(2022.2) \mathrm{kg} / \mathrm{m} 3$. The expansion of polymer-mortar composites was kept in limitation slandered and the lowest expansion was (0.032\%) for $15 \%$ polymer. All percentages of the polymer prevent water penetration under high pressure to the concrete cube. The lowest thermal conductivity of polymer-mortar composites for post-cured at $30 \%$ which was (0.6146)W/m.k. The lowest velocity obtained was at room temperature for $15 \%$ of epoxy. It was concluded that the addition of polymer enhance the insulation properties especially waterproofing..
\end{abstract}

Keywords: Insulation; thermal performance; polymercement composite; waterproofing

\section{Introduction}

Over the years, there has been a number of researches on the subject of polymer mortar, polymer-modified mortar and polymer blended mortar. Polymer modified mortar is a composite material that consists of two solid phases: aggregates continuously by material a binder containing the cementation phase and the polymer phase. Polymer-modified mortar is made by mixing polymer or monomer with fresh cement mortar composites in dispersed, dry or liquid form and then curing. Currently, these materials are mainly used as common construction materials due to their comparative performance, multifunctional, and stability in the evaluation of conventional cement concrete. The properties of the composite material are not only derived from its components, but also the synergistic effect[1]. Mortars are definitely used to binding materials, but also to align a consistent finish to walls and floors. They also used for repair, insulation, and renovation[2]. Polymers, in general, have properties such as low thermal conductivity, sound insulation, waterproofing, and lightweight. Thus, one can

*Corresponding Author: Baraamahdi20@gmail.com 
take advantage of these properties in the construction industry which will supplement a new material for construction[3]. (M.V. Diamanti, et al. 2013)[4] had accompanied the effectiveness of two cementations coating modified with acrylic polymer specimens that preparation involved the molding of polymermodified mortars consisting of ordinary portland cement - water/cement (W/C) ratio 0.50 and silica sand particles with a polymer-tocement $(\mathrm{P} / \mathrm{C})$ ratio of 0.35 and 0.55 . Coverings act as a physical barrier, reducing water and chloride penetration into the concrete. The existence of the polymer allows diminishing coating porosity. (Ru Wang, et al. 2013)[5]. Had studied the capillary water absorption, permeability, and Cracking of modified cement mortars with three Founded polymers (Dispersion of styrene-butadiene rubber, styrene-acrylic copolymer powder, and dispersion of styrene-acrylic copolymer). The ratio of polymer to cement was weight percentage $(0,1,3,5,8,10,12,15,18,20)$. Results indicate that with increasing polymer content, especially when the polymer/cement ratio increases from $0 \%$ to $5 \%$, the absorption is significantly reduced of capillary water and the depth of penetration of water into the mortar. If the polymer / cement exceeds 15 percent, the increase in polymer/cement in all mortars has no effect on the absorption and penetration of capillary water. The cracking weighted value is used with styrene-butadiene rubber and the styrene-acrylic copolymer powder is superior to the dispersion of styrene-acrylic copolymer.

\section{Aim}

The aim of this work is to enhance some insulation properties thermal conductivity, expansion and permeability by addition epoxy to cement mortar.

\section{Experimental approach}

\subsection{Materials}

\subsubsection{Cement}

The cement used in this work is a common Portland cement, commercially known (Aljessr). It is stored in a dry area and tested at (National Center for Laboratories and Construction Research, Baghdad, Iraq ) to reduce the effect of moisture on cement properties. The chemical and physical properties of this cement are listed in Table 1. Use it is compares with the Iraqi Reference Guide Index Number (198) and the Ministry of Planning / Central Agency for Standardization and Quality Control Manual 198/1990 [4].

Table 1. Chemical composition and physical properties of cement.

\begin{tabular}{|c|c|c|c|c|c|}
\hline \multicolumn{3}{|c|}{ Chemical composition } & \multicolumn{3}{|c|}{ Physical properties } \\
\hline Item & $\begin{array}{c}\text { Content } \\
\%\end{array}$ & $\begin{array}{l}\text { Spec. } \\
\text { Limit }\end{array}$ & Item & $\begin{array}{r}\text { Test } \\
\text { result }\end{array}$ & $\begin{array}{l}\text { Spec. } \\
\text { Limit }\end{array}$ \\
\hline $\mathrm{SiO}_{2}$ & 21.03 & & $\begin{array}{l}\text { Fineness } \\
\left(\mathrm{m}^{2} / \mathrm{kg}\right)\end{array}$ & 370 & 320 \\
\hline $\mathrm{Al}_{2} \mathrm{O}_{3}$ & 4.40 & & $\begin{array}{c}\text { Autoclave } \\
\text { exp. }\end{array}$ & 0.32 & $0.8 \%$ \\
\hline $\mathrm{Fe}_{2} \mathrm{O}_{3}$ & 3.17 & & \multirow{3}{*}{$\begin{array}{c}\text { Compressive } \\
\text { strength } \\
\text { (Mpa) } \\
\text { 3-days age }\end{array}$} & \multirow[b]{3}{*}{29.5} & \multirow[b]{3}{*}{$\geq 15.0$} \\
\hline $\mathrm{Cao}$ & 62.66 & & & & \\
\hline Mgo & 1.77 & $\begin{array}{c}5.0 \\
\text { Max }\end{array}$ & & & \\
\hline & & & \multirow{2}{*}{$\begin{array}{l}\text { Compressive } \\
\text { strength } \\
\text { (Mpa) } \\
\text { 7-days age }\end{array}$} & \multirow[b]{2}{*}{34} & \multirow[b]{2}{*}{$\geq 23.0$} \\
\hline \multirow[t]{2}{*}{$\mathrm{SO}_{3}$} & \multirow[t]{2}{*}{2.2} & \multirow[t]{2}{*}{$\begin{array}{c}2.8 \\
\operatorname{Max}\end{array}$} & & & \\
\hline & & & \multirow{2}{*}{$\begin{array}{c}\text { Time of } \\
\text { setting } \\
\text { Initial (min.) }\end{array}$} & \multirow[b]{2}{*}{35} & \multirow[b]{2}{*}{$\leq 45$} \\
\hline L.O.I & 1.9 & $\begin{array}{c}4.0 \\
\text { Max }\end{array}$ & & & \\
\hline $\begin{array}{l}\text { I.R.[Insoluble } \\
\text { Residue \%] }\end{array}$ & 0.99 & 1.5 & $\begin{array}{c}\text { Time of } \\
\text { setting } \\
\text { Final (hour) }\end{array}$ & 5.25 & $\begin{array}{c}10 \\
\text { Max. }\end{array}$ \\
\hline
\end{tabular}

\subsubsection{Fine Aggregate}

The fine aggregate used in studied is according to the Iraqi specification No.45 of 1984 for Cement. Brought from area where they were bringing models that are all located within the zone 2 gradient specification under Iraqi specification [4] as shown in Table 2. 
Table 2. Fine aggregate grading.

\begin{tabular}{|c|c|c|}
\hline $\begin{array}{c}\text { Sieve size } \\
(\mathrm{mm})\end{array}$ & $\begin{array}{c}\text { \% Passing by } \\
\text { Weight }\end{array}$ & $\begin{array}{c}\text { Specific } \\
\text { Limit }\end{array}$ \\
\hline 4.750 & 92.30 & $90.0-100.0$ \\
\hline 2.360 & 83.70 & $70.0-100.0$ \\
\hline 1.180 & 73.90 & $55.0-90.0$ \\
\hline 0.600 & 51.80 & $53.0-59.0$ \\
\hline 0.300 & 20.20 & $8.0-30.0$ \\
\hline 0.150 & 4.60 & $0.0-10.0$ \\
\hline $\begin{array}{c}\text { Salts } \\
\text { Percentage } \\
\%\end{array}$ & 0.400 & $\leq 0.50$ \\
\hline
\end{tabular}

\subsubsection{Polymers}

Epoxy type (EUXIT 52) is used in all the experiments. Table (3) shows the properties of the common epoxy resin. Epoxy has two components: Hardener and resin. The hardener reacts with the resin and hence it is converted from viscous liquid to a hard solid material (i.e. Polymer with a high molecular weight). In this study, a ratio of 1 part of hardener to 2 parts of resin (by weight) is used. In general, a strong adhesion quality good mechanical properties of epoxy can be obtained with low-cost, comparing to other types of thermoset polymer resins.

Table 3. Typical properties of epoxy from supplier

\begin{tabular}{|c|c|}
\hline \multicolumn{1}{|c|}{ Properties } & Value \\
\hline $\begin{array}{c}\text { Tensile } \\
\text { strength }\end{array}$ & $36(\mathrm{mpa})$ \\
\hline $\begin{array}{c}\text { Compressive } \\
\text { strength }\end{array}$ & $70(\mathrm{mpa})$ \\
\hline Elongation & $31 \%$. \\
\hline Full curing & days at $35^{\circ} \mathrm{C}$ \\
\hline
\end{tabular}

\subsection{Experimental work}

Two sets of the mixture were prepared that consist of mortar and polymer to fabricate the polymer-mortar composite one cured at room temperature and other post-curing at $50{ }^{\circ} \mathrm{C}$ for two hours according to the average temperature in the Iraqi summer. Each set includes a mortar with a ratio (1:1) (cement-sand) without water. The polymer was epoxy which is added to the mortar after mixing the resin with the hardener in the proportion of $(1: 2)$. The set consists of different percentages of polymer - mortar ratio $(15,20$, and 30\%). The polymer-mortar with different proportions was prepared by mixing firstly the resin with hardener, then after complete homogenization, the polymer-mortar was introduced in the mixture. An electrical mixer was used in preparing the mixtures to achieve a suitable homogeneity. After mixing, the polymer mortars were poured into the molds which were coated with mineral oil to prevent adhesion with the polymer-mortar composite. The polymer-mortar casting was accomplished in three layers. Each layer was compacted by using a vibrating device (Viatest Co. German) for 1-1.5 min. Until minimum air bubbles emerged to the surface of the casting. The following mechanical characteristics were experimentally tested: velocity test on cube specimens of $(50 * 50 * 50) \mathrm{mm}$ sizes, thermal conductivity specimens of sizes $(100 * 50 * 20)$ $\mathrm{mm}$, velocity test on cube specimens of ( $50 * 50 * 50) \mathrm{mm}$ and velocity test coating (2$3) \mathrm{mm}$ on concrete cube specimens of ( $100 * 100 * 100) \mathrm{mm}$.

\section{Tests}

\subsection{Expansion test}

This test was performed to determine autoclave extension in accordance with ASTM Standards C151-09 [5]. Specimens of the Polymer-mortar composites $(250 \times 5 \times 25) \mathrm{mm}$ are molded with. 
The humid atmosphere was maintained at $90 \%$ and temperature $200 \mathrm{C}$ for 24 hours. Samples, then, were removed after 24 hours \pm 30 minutes from humid weather (acquire a duration comparator read directly for each specimen). The autoclave was set at room temperature in a rack to expose all sides of the specimen to saturated steam. The autoclave must have enough water to maintain a saturated vapor atmosphere at an elementary temperature of 20 to $28^{\circ} \mathrm{C}$. Steam usually absorbs between 7 and 10 percent of the autoclave's volume. After that, the vent valve was opened before the steam escapes to leave the air from the autoclave through the early part of the time for the heating. Increasing the autoclave temperature at a rate after closing the valve which increases the steam pressure gauge to 2.0 pa from 45 to 75 minutes from the moment the temperature was turned on. The pressure is maintained at 260.07 Mpa for three hours, which the temperature becomes $216^{\circ} \mathrm{C}$. The heat supply at the end of the 3-h cycle was turn off. This was to cool the autoclave and the pressure was less than 0.070 Mpa to such a speed. The remaining pressure then was slowly released at the end of the period and cool the water to $23^{\circ} \mathrm{C}$. This operation was partially opened by the vent valve which leads to reaching the atmospheric pressure. Finally, samples are removed and the comparison length was taken. The length change of the test specimen was calculated by subtracting the length comparator reading from the autoclaving before autoclaving and report the percentage of the length for the effects for the test specimen to the nearest 0.01 .

\subsection{Penetration of water at high pressure}

According to EN 12390-8 [6], the European standard AT 315 apparatus of polymer-cement compositions were coated on top of the concrete cube. This operation is supplied to calculate the water permeability for the concrete. The apparatus is connected to a simple air compresser that can continuously assure at least 5.0 bar of compressed air and is equipped with oil filter and a dehumidifier. The laboratory water supply and drainage system was connected and after at least 28 days the samples were tested. The specimen was placed on the apparatus for testing. The water pressure acting on the tested area (which is $75 \mathrm{~mm}$ in diameter) is in the center of the lower surface.

\subsection{Thermal conductivity}

The composites polymer-mortar specimens with dimensions of $(100 * 50 * 20 \mathrm{~mm})$ were prepared. The thermal conductivity determined by QTM500 in accordance with ASTM C, 1113-09[7] makes speedy and easy measurement of all types of materials. Stick sensor probe on specimen surface of thermal equilibrium, and press (START) key The results of the measurements will show up according to material properties.

\subsection{Ultrasonic Pulse Velocity Test}

This test was approved in accordance with the British standard BS1881: Part 203 [8]. The ultrasonic non-destructive activity tester (PUNDIT Lab PROCEQ Co.) Was used. Two transducers were fitted to the instrument cables: one served as a transmitter for ultrasonic pulses, and the other as a receiver. Two transducers were placed on the surface of the sample using a coupling agent to ensure good transmission. Grease or petroleum jelly was applied between the tested surfaces of the sample and the contact faces of the transducers to ensure good contact. In this test, the pulse of longitudinal vibration with resonant frequency envies of $54 \mathrm{kHz}$ is generated by the electro-acoustic transducer, and then converted to an electrical signal by the receiver transducer. The transport time of the 
pulse is applied by an electronic timing circuit. Pulse velocity (V) in ( $\mathrm{M} / \mathrm{s})$.

\section{Results and discussion}

\subsection{Expansion test}

The values of the extents of the polymer mortar composites varied between $(0.032,0.032,0.055$, 0.316) for Different concentrations of epoxy $(0.15,20,30 \%)$, respectively, as shown in Fig. (4.1). the polymer-mortar composites sample expansion was increase as the percentage of the polymer was increased this was attributed to several reasons. The filler (sand) has low thermal expansion and tighter than polymer so as the increase of filler proportional in polymer composite the expansion decrease. The polymer has low strength so as polymer mortar composites with high polymer percentage after exposure to autoclave (humidity, pressure, and temperature), the majority of cracks are found in it.

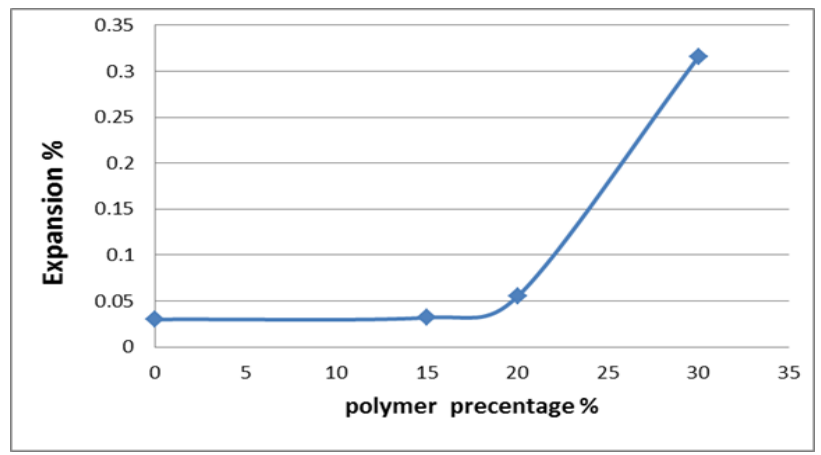

Figure 1.Expansion of different polymer - mortar composites.

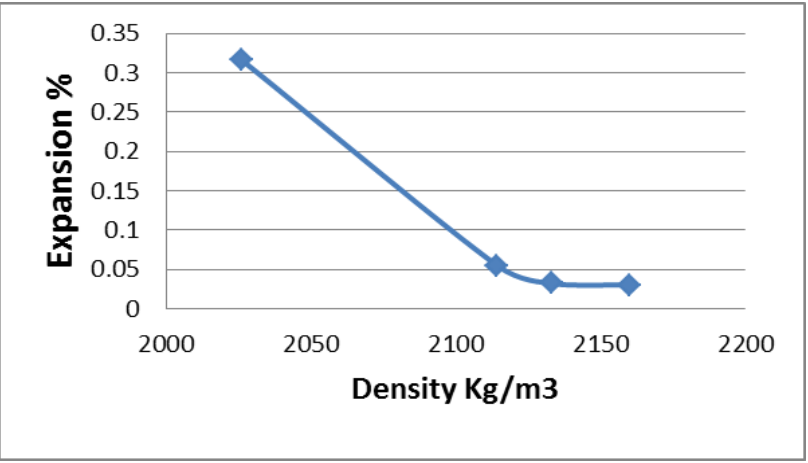

Figure 2. Expansion of different polymer - mortar .composites with density

\subsection{Penetration of water under high pressure test}

After the concrete was coated by different polymer-mortar composites the was tested. The values of water permeability to the concrete are equal to zero as shown in the table3. Due to polymer chemicals injects into the pores of the mortar. Some open holes are covered by a polymer film formed by polymer inclusion; Therefore, open porosity was reduced, and larger pores were tightened, making it more difficult for water to enter the mortar, according to physical principles.

Table 3. Permeability of different polymer -mortar ratio

\begin{tabular}{|c|c|}
\hline $\begin{array}{c}\text { Polymer- } \\
\text { mortar ratio \% }\end{array}$ & $\begin{array}{c}\text { Permeability } \\
(\mathrm{mm})\end{array}$ \\
\hline 0 & 17 \\
\hline 15 & 0 \\
\hline 20 & 0 \\
\hline 30 & 0 \\
\hline
\end{tabular}

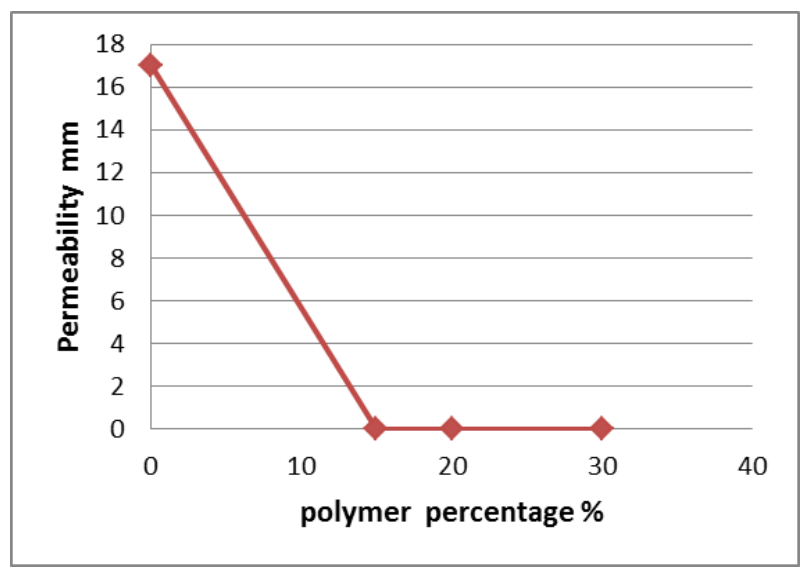

Figure3. Permeability of different polymer -mortar composites.

\subsection{Thermal conductivity}

The results of the thermal conductivity of different polymer-mortar composites are shown in Fig. 4. The thermal conductivity of all samples increased as the polymer addition 
decreases due to the polymer represented insulation material, therefore, improves the thermal insulation because the polymer may form an interface between the fillers. When polymer-mortar composites were exposed to post-curing, very little reduction in thermal conductivity was noticed. This might be due to cross-linking and stacking of polymer molecules.

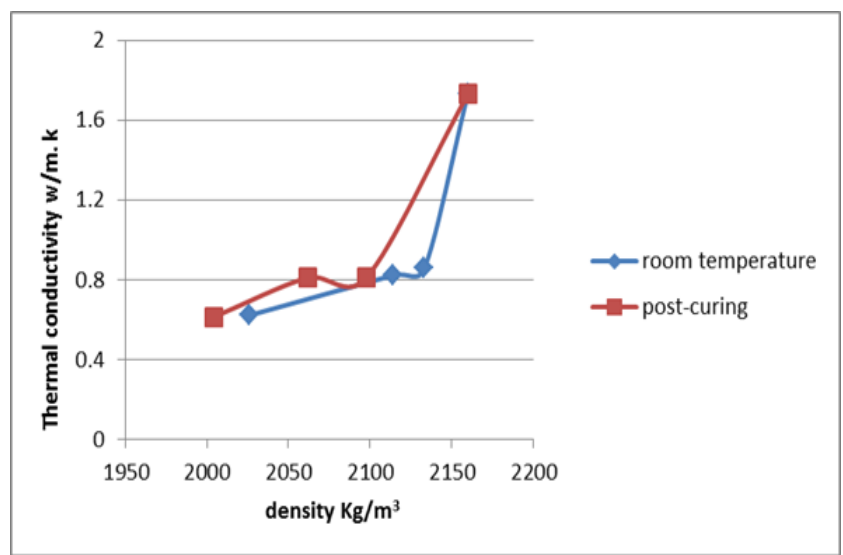

Figure 4. Thermal conductivity of different polymer mortar ratio a Post -cured and room temperature cured

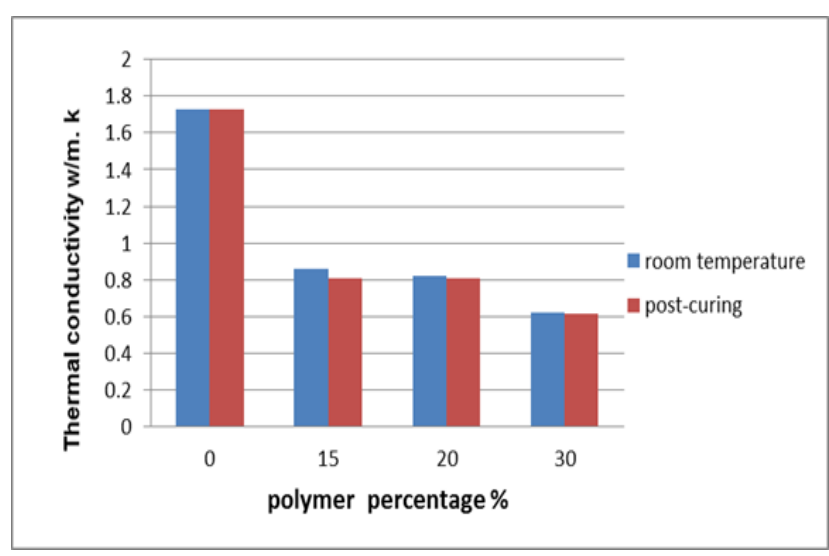

Figure 5. Comparison between the thermal conductivity of different polymer cement composites when post-curing at $50^{\circ} \mathrm{c}$ and room temperature cure.

As a comparison between post-curing and curing at room temperature, it was observed from Figs .5and 4 that: High polymer-mortar ratio has low thermal conductivity. The thermal conductivity of the polymer-mortar composites for post-cured lower from that room temperature. All percentage of the polymer reduces the thermal conductivity when added to the mortar. Thermal conductivity decrease with density decrease.

\subsection{Ultrasonic test}

The values of velocity for different polymermortar composites are shown in Fig.6. Several observations can be drawn from Figs. 6and 7. High polymer percentage increases homogeneity due to increases adhesion and reduces void between filler. The velocity of polymer-mortar composites for the post-cured is higher than room temperature, due increase in cross-linked that leads to increases the homogeneity of the composites.

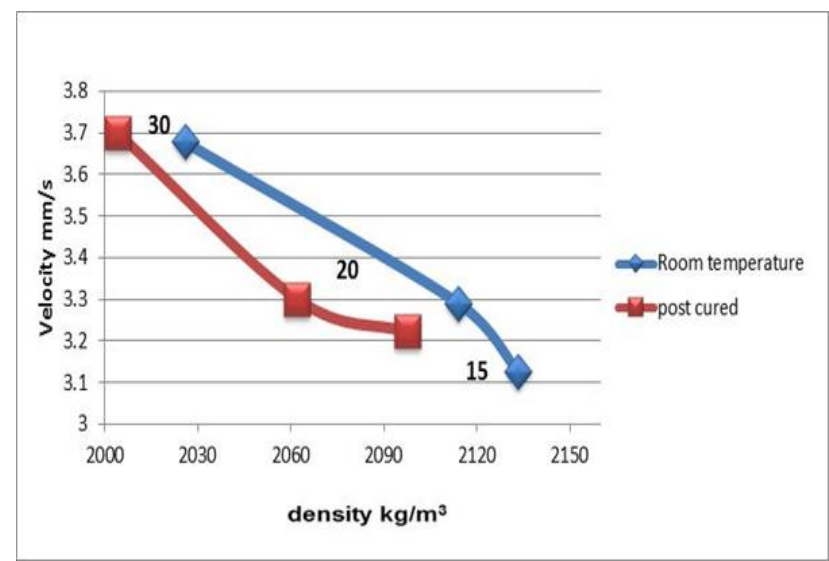

Figure 6. Ultrasonic velocity of different polymer mortar ratio at Post -cured and room temperature cure

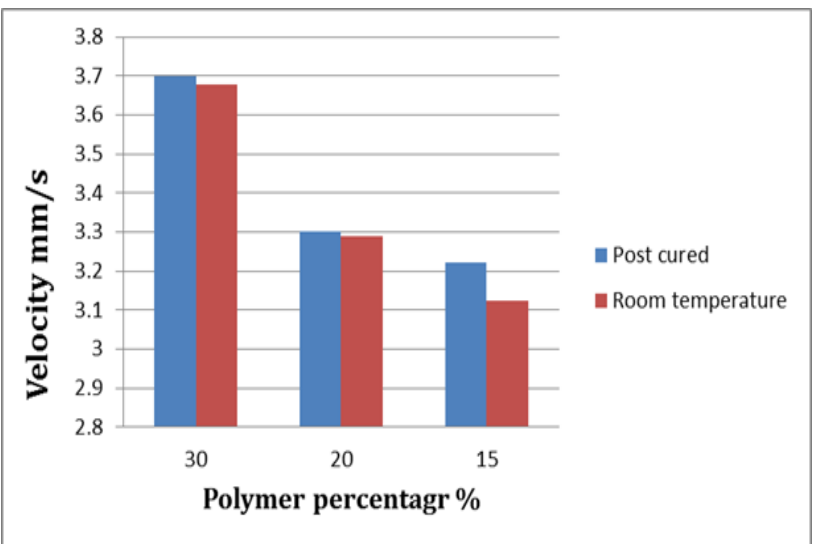

Figure7. Comparison between the velocity of different polymer -cement at post- curing at $50^{\circ} \mathrm{c}$ and room temperature. 


\section{Conclusion}

1. All polymer-mortar permeability test showed superior properties, which gave zero water entry at high pressure.

2. Polymer-mortar composite did not change its properties to the standard limit.

3. Thermal the conductivity of Polymer Cement composites increase as polymer ratio decreases .Post-curing has lower thermal conductivity than room temperature curing.

4. The ultrasonic velocity of polymercement composites is reduced when the percentage of the polymer is reduced and cured at room temperature

\section{Conflict of interest}

The publication of this article cause no conflict of interest

\section{References}

1. Ganesan, S., et al. 2014 Performance of polymer modified mortar with different dosage of polymeric modifier. In MATEC Web of Conferences. EDP Sciences.

2. Ohama, Y. (1995). "Handbook of polymermodified concrete and mortars: properties and process technology". William Andrew.

3. Chen, H., et al. (2016). Thermal conductivity of polymer-based composites: Fundamentals and applications. Progress in Polymer Science, Vol. 59(No. Pp. 41-85.

4. Diamanti, M.V., et al. (2013). Effect of polymer modified cementitious coatings on water and chloride permeability in concrete. Construction and Building Materials, Vol. 49(No. Pp. 720-728.

5. Wang, R., X.X. Shi, and P.M. Wang. 2013 Recent research on polymer-modified cement mortar in China. In Advanced Materials Research. Trans Tech Publ.
6. Mohsin, A.I. and B.M. Fahad. (2015). Improve the Acoustic Impedance and Thermal Conductivity of Mortar by Adding Recycled Rubber. Journal Of Modern Engineering Research (IJMER), Vol. 5(No. Pp. 9-16.

7. Wood, S.G., et al. (2017). Five-hour autoclave test for determining potential alkali-silica reactivity of concrete aggregates: a multi-laboratory study. Advances in Civil Engineering Materials, Vol. 6(1), No. 1, pp. 550-563.

8. EN, B.S. (2000). 12390-8," Depth of penetration of water under pressure. British Standards Institution, Vol. No .

9. ASTM, C. (2004). 1113-99: Standard test method for thermal conductivity of refractories by hot wire (Platinum Resistance Thermometer Technique). American Society for Testing and Materials-ASTMInternational .

10. British standard BS1881 : part 203:1986, 2003. 